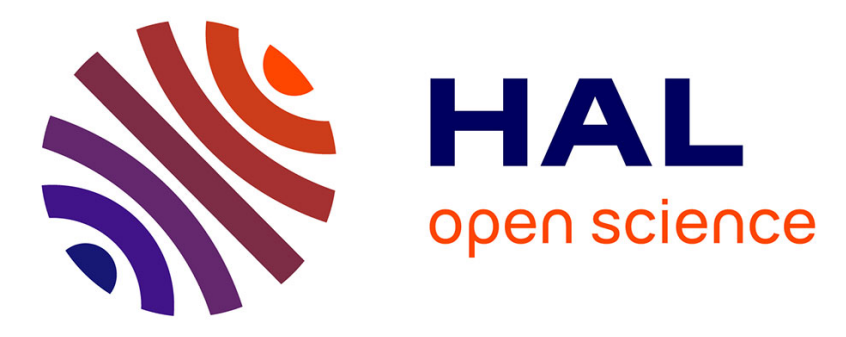

\title{
Use of very-high-dose olanzapine in treatment-resistant schizophrenia
}

\author{
Jean-Marie Batail, B. Langrée, G. Robert, S. Bleher, M.-C. Verdier, E. \\ Bellissant, Bruno Millet, Dominique Drapier
}

\section{- To cite this version:}

Jean-Marie Batail, B. Langrée, G. Robert, S. Bleher, M.-C. Verdier, et al.. Use of very-high-dose olanzapine in treatment-resistant schizophrenia. Schizophrenia Research, 2014, 159 (2-3), pp.411-414. 10.1016/j.schres.2014.09.020 . hal-01147041

\section{HAL Id: hal-01147041 https://hal-univ-rennes1.archives-ouvertes.fr/hal-01147041}

Submitted on 14 Sep 2015

HAL is a multi-disciplinary open access archive for the deposit and dissemination of scientific research documents, whether they are published or not. The documents may come from teaching and research institutions in France or abroad, or from public or private research centers.
L'archive ouverte pluridisciplinaire HAL, est destinée au dépôt et à la diffusion de documents scientifiques de niveau recherche, publiés ou non, émanant des établissements d'enseignement et de recherche français ou étrangers, des laboratoires publics ou privés. 


\section{Use of very-high-dose olanzapine in treatment-resistant schizophrenia}

J.-M. Batail ${ }^{1,2}$, B. Langrée ${ }^{3,5,6}$, G. Robert ${ }^{1,2}$, S. Bleher ${ }^{1,2}$, M.-C. Verdier ${ }^{4,5,6}$, E. Bellissant ${ }^{4,5,6}$, B. Millet ${ }^{1,2}$, D. Drapier ${ }^{1,2}$.

${ }^{1}$ Academic Psychiatry Department, Centre Hospitalier Guillaume Régnier, Rennes, France.

${ }^{2}$ EA 4712 Behavior and Basal Ganglia, CHU Rennes, Rennes 1 University, France.

${ }^{3}$ Pharmacy Departement, Centre Hospitalier Guillaume Régnier, Rennes, France.

${ }^{4}$ Rennes University Hospital, Department of Clinical and Biological Pharmacology and Pharmacovigilance, Pharmacoepidemiology and Drug Information Center, Rennes, France.

${ }^{5}$ Laboratory of Experimental and Clinical Pharmacology, Rennes 1 University, Faculty of Medicine, Rennes, France.

${ }^{6}$ Inserm, CIC-P 1414 Clinical Investigation Center, Rennes, France.

Corresponding author:

Jean-Marie Batail, Service Hospitalo-Universitaire de Psychiatrie d'Adulte, Centre Hospitalier Guillaume Régnier, 108 avenue du Général Leclerc, 35703 Rennes, France.

Tel.: +3329933 39 37; Fax: +3329933 3972 .

e-mail: jeanmariebatail@gmail.com

\section{Introduction}

Schizophrenia is a debilitating illness with an estimated lifetime prevalence of around $0.7 \%$ (McGrath et al., 2008). In 2001, the World Health Organization described schizophrenia as one of the ten most disabling diseases in the world (Saraceno et al., 2005). It affects nearly all areas of patients' social, family and professional lives. Its cost for society is high, both directly (hospitalizations, treatment, dysfunctional social skills) and indirectly (loss of productivity) (McGrath et al., 2008). Its course can be marked by resistance to antipsychotic treatment, meaning that therapeutic support is sometimes challenging for the practitioner, with results that are partial and unsatisfactory.

Despite the development of a new generation of molecules, bringing greater efficacy and fewer side effects, some patients still fail to respond to treatment. The rate of treatmentresistant schizophrenia (TRS) is estimated to be between 30 and $60 \%$, depending on which criteria are used (Solanki et al., 2009). If first-line treatments prove ineffective, there are still many options available, not least the gold standard, clozapine. If this fails, then clozapine 
augmentation is one possible solution, not to mention the use of alternative antipsychotics, anticonvulsants or nonpharmacological options, including electroconvulsive therapy and transcranial magnetic stimulation for resistant auditory hallucinations (Mcilwain et al., 2011). Another therapeutic option is the prescription of atypical antipsychotics at high doses. Since the late 1990s, high-dose olanzapine has become a worthwhile alternative for clozapineresistant or intolerant patients. Three out of four randomized, double-blind clinical trials have concluded that high-dose olanzapine $(25-45 \mathrm{mg} / \mathrm{d})$ is just as effective as clozapine (100-600 $\mathrm{mg} / \mathrm{d}$ ), and is also well tolerated (Tollefson et al., 2001; Bitter et al., 2004; Meltzer et al., 2008). Only one study, conducted in patients aged 10-18 years and treated with $10-30 \mathrm{mg} / \mathrm{d}$, failed to find any advantage to prescribing high-dose olanzapine versus clozapine (Kumra et al., 2008). A number of case reports have underlined the usefulness of high-dose olanzapine. Many of them describe its use at doses of between $25 \mathrm{mg} / \mathrm{d}$ (Martín et al., 1997; RodríguezPérez et al., 2002) and 60 mg/d (Lerner, 2003; Qadri et al., 2006). They all highlight its good neurological tolerance, but report weight gain as a common side effect. In a recently published case report, we reported the case of two patients who were treated with very high doses of olanzapine (80 and $100 \mathrm{mg} / \mathrm{d}$ ) (Batail et al., 2012). They both had TRS and had reached a therapeutic dead end. One of them had contracted a fever owing to clozapinerelated agranulocytosis. The other patient had early-onset TRS, and high-dose olanzapine was tried as an alternative before resorting to clozapine (Batail et al., 2012). They both became responders at doses above $60 \mathrm{mg} / \mathrm{d}$, with good tolerance except for a 10-kg weight gain in one, controlled by dietary measures. In this report, we raised the question of the psychopharmacological mechanism behind the therapeutic response at such high doses. Since then, the question of the efficacy and tolerance of high-dose olanzapine has come to the fore. Why are such high doses needed to elicit a clinical response in these patients? Do patients with TRS have lower plasma concentrations of olanzapine as a result of reduced gastrointestinal absorption or increased hepatic metabolization? In other words, how far do pharmacokinetic properties matter? To our knowledge, there are no published data on the pharmacokinetics of olanzapine at doses above $60 \mathrm{mg} / \mathrm{d}$. According to the literature, the dose-concentration relationship remains linear for olanzapine regimens at doses $<60 \mathrm{mg} / \mathrm{d}$ (Callaghan et al., 1999; Mauri et al., 2007). Therefore, patients who are resistant to conventional olanzapine doses may have either linear pharmacokinetic characteristics, implying that pharmacodynamic factors come into play in treatment resistance, or nonlinear pharmacokinetics, which would justify an increasing dose strategy in order to achieve an 
effective olanzapine blood concentration. The first option would appear to be the most relevant.

In the present study, we assessed the pharmacokinetics of olanzapine at both conventional and high doses. We hypothesized that there is a linear dose-concentration relationship at very high doses, just as the literature have highlighted it at doses $<60 \mathrm{mg} / \mathrm{d}$.

\section{Methods}

\subsection{Patient population}

Participants were recruited at Rennes University Psychiatric Hospital either as inpatients or as outpatients. We included patients who had been diagnosed with schizophrenia or schizoaffective disorder in accordance with DSM-IV criteria and were being treated with olanzapine. Exclusion criteria were other DSM-IV diagnoses (bipolar disorder, autism, etc.) and addictions (alcohol, cannabis, heroin, cocaine, etc.).

The participants were aware of the purpose of the study, and gave their informed consent. The study was approved by the Human Research Ethics Committee of Rennes University Hospital (Brittany, France) and was conducted in accordance with the Declaration of Helsinki and its subsequent revisions.

\subsection{Study design}

We implemented a prospective, observational, open-study design. In accordance with the literature, patients were included after a steady-state olanzapine regimen lasting at least 8 days (Callaghan et al., 1999). They were assessed once, either in the course of their hospitalization or during an outpatient consultation.

\subsubsection{Clinical assessment}

The clinical assessment was conducted by an experienced psychiatrist.

We recorded the participants' general characteristics, including age and sex, tobacco, tea and/or coffee consumption, psychiatric, medical and surgical history, olanzapine treatment history, and history of other treatments. 
In line with the literature, therapeutic side effects were assessed with two scales: the Extrapyramidal Syndrome Rating Scale (ESRS), which focuses on neurological side effects, and the Udvalg for Kliniske Undersogelser (UKU), a more general scale that measures psychic, neurological, neurovegetative and other side effects. Schizophrenic symptoms were assessed by means of the Positive and Negative Syndrome Scale (PANSS). The Clinical Global Impression scale (CGI) yielded a qualitative assessment.

\subsubsection{Biological assessment}

\subsubsection{Methodology}

In order to study trough concentrations of olanzapine and N-desmethyl olanzapine blood levels, blood samples were taken at least 21-24 hours after the last dose. For patients who were on high doses taken twice daily (4 patients), blood sampling was done 12 hours after the last dose.

Patients on very high-dose olanzapine (> $60 \mathrm{mg} / \mathrm{d}$ ) underwent weekly biological assessments (blood count, liver function) and electrocardiograms.

\subsubsection{Serum sampling}

The serum samples were collected as follows: 7-10 $\mathrm{ml}$ of venous blood was collected in vacuum tubes containing heparin directly in the ward during routine blood tests.

The analyses were performed on a Thermo ${ }^{\mathrm{TM}}$ (San Jose, CA, USA) TSQ Quantum HPLCcoupled tandem mass spectrometer (LC-MS/MS).

Olanzapine and $\mathrm{N}$-desmethyl olanzapine serum concentrations were obtained with a fully validated LC-MS/MS analytical method commercialized by Chromsystems Instruments \& Chemicals GmbH (Gräfelfing, Germany) called "MassTox® TDM Series A - Neuroleptics 1", featuring calibrators, quality controls, solvents and an analytical column.

\subsection{Statistical analyses}


Statistical analyses were performed on all included and assessed patients (intention-to-treat analysis) with R software (http://www.R-project.org/). All results are reported as means $\pm S D$ for continuous variables and rate for discrete variables. In line with the literature, the UKU subscale scores are described in terms of side effect occurrences. ESRS subcale scores are reported as means $\pm S D$. The significance threshold for all the tests was set at $5 \%(p<0.05)$.

A descriptive analysis of clinical characteristics and the dose-concentration relationship was carried out for the whole group. For the dose-concentration relationship, after calculating Pearson's correlation coefficient, we used a linear model to assess the effects of sex, age, body mass index (BMI) tobacco (number of cigarettes per day), and coffee/tea consumption.

\section{Results}

A total of 50 patients were included in the study.

\subsection{Whole group analysis}

Clinical characteristics are summarized in Table 1. Age in the total sample ranged between 19 and 60 years. Illness severity, as assessed by the mean score on the severity scale of the CGI, was moderate.

Co-medications were benzodiazepine (12 patients; $26.09 \%)$, anticonvulsants $(3 ; 6.52 \%)$, other neuroleptics (cyamemazine or loxapine) $(11 ; 23.91 \%)$, antiparkinsonism drugs $(3 ; 6.52 \%)$, and antidepressants $(5 ; 10.87 \%)$. Pharmacological and biological characteristics are summarized in Table 2.

\subsubsection{Dose-concentration relationship}

Figure 1 illustrates the relationship between trough olanzapine concentration and the daily oral dose of olanzapine. We found a link between these two variables (Pearson's $r=0.83, p<$ $0.001,95 \%$ CI $[0.72,0.90])$. Linear regression coordinates were $y=1.91 x+10.25$.

A linear model used to assess the effects of sex, age, tobacco (number of cigarettes per day), and coffee/tea consumption on the dose-concentration relationship revealed negative effects of tobacco $(p<0.005)$ and coffee/tea consumption $(p<0.001)$, but no significant effect of sex (positive effect of female sex, $p=0.06$ ). 


\subsubsection{Concentration-tolerance relationship}

Very few secondary side effects were reported, whatever the olanzapine regimen, and there was a low reported occurrence of neurological signs. Dyskinesia was described in two patients, one at $80 \mathrm{mg} / \mathrm{d}$ (Olanzapine Trough Concentration $($ OTC) $=186.3 \mathrm{ng} / \mathrm{ml}$ ), the other at $15 \mathrm{mg} / \mathrm{d}($ OTC $=48.1 \mathrm{ng} / \mathrm{ml})$. Dystonia affected one patient at $80 \mathrm{mg} / \mathrm{d}($ OTC $=186.3$ $\mathrm{ng} / \mathrm{ml})$. Parkinsonism was observed in four patients, one at $80 \mathrm{mg} / \mathrm{d}(106.1 \mathrm{ng} / \mathrm{ml})$, one at 40 $\mathrm{mg} / \mathrm{d}(\mathrm{OTC}=71.8 \mathrm{ng} / \mathrm{ml})$, and two at $10 \mathrm{mg} / \mathrm{d}(\mathrm{OTC}=40.1 \mathrm{ng} / \mathrm{ml}$, and OTC $=32.4 \mathrm{ng} / \mathrm{ml})$. In two of them, loxapine or cyamemazine had been co-prescribed. Three patients who were treated with $20($ OTC $=34.1 \mathrm{ng} / \mathrm{ml}), 30($ OTC $=60 \mathrm{ng} / \mathrm{ml})$ or $40 \mathrm{mg} / \mathrm{d}($ OTC $=71.8 \mathrm{ng} / \mathrm{ml})$ had akathisia. All three of them were also receiving loxapine or cyamemazine. All the neurological side effects were given light or moderate intensity ratings.

\section{Discussion}

Ours was the first study to explore the pharmacokinetics of olanzapine used at doses above 60 $\mathrm{mg} / \mathrm{d}$ in patients with schizophrenia.

\subsection{Clinical considerations}

Our sample comprised a majority of men $(60 \%)$ and smokers $(70 \%)$, which is in accordance with the literature (McGrath et al., 2008; Mueser McGurk, 2004; Van Os et Kapur, 2009). Age was homogeneously distributed between the ages of 19 and 60 years, with a majority aged in their thirties. Mean disease duration was therefore approximately 10 years. The response rate was $68 \%$, which corresponds to the upper part of the range that is classically reported (0-76\%) (Suzuki et al., 2011). A part of patients, included during consultations, had been stable for a long time, which may have contributed to this result.

\subsection{Pharmacological and biological aspects}

First, the mean daily oral dose of olanzapine for the whole sample was $31.3 \mathrm{mg} / \mathrm{d}$, that is, higher than the dose currently recommended by the health authorities. Therefore, the 
biological characteristics of our sample exhibited the same upward trend as the pharmacological one. The trough olanzapine concentration $(70.02 \mathrm{ng} / \mathrm{ml})$ was close to the upper limit of the therapeutic reference range (between 20 and $80 \mathrm{ng} / \mathrm{ml}$ (Hiemke et al., 2011)) recommended by the Arbeitsgemeinschaft für Neuropsychopharmakologie und Pharmakopsychiatrie (AGNP). The same is true for the C / D average in our sample was 2.34 $\mathrm{ng} / \mathrm{ml} / \mathrm{mg} /$ day for a recommended range between 0.87 and 2.38 (Hiemke et al., 2011).

\subsection{Dose-concentration relationship}

We observed a strong linear correlation (Pearson's $r=0.83$ ) between the olanzapine daily oral dose and trough olanzapine concentration, which validated our main hypothesis of a linear dose-concentration relationship for olanzapine, even at very high doses. This result is consistent with the literature (Callaghan et al., 1999; Mauri et al., 2007). Tobacco significantly decreased the olanzapine plasma concentration in our sample, in accordance with current knowledge (Callaghan et al., 1999; Carrillo et al., 2003; Mauri et al., 2007; Nosawa et al., 2008; Patel et al., 2011; Weiss et al., 2005): tobacco has been identified as an inducer of cytochrome P450 1A2, with a consequent multiplication of enzymatic activity by a factor of 2-6 (Carrillo et al., 2003). A negative effect of tea/coffee consumption was also found. There are very few data on the inductive effects of caffeine (Perera et al., 2012) on olanzapine metabolism. There is a similar dearth of information about the inductive effect of green tea extract on clozapine metabolism (Jang et al., 2005) and the activity of cytochrome P450 1A2 (Schönthal, 2011). Data for green tea and coffee should be analyzed separately, in order to disentangle their effects on olanzapine metabolism.

\subsection{Concentration-tolerance relationship}

In our sample, olanzapine treatment was well tolerated, particularly with regard to neurological features. This result is in accordance with the literature (Callaghan et al., 1999; Mauri et al., 2007). The neurological side effects we observed were in patients treated with doses between 10 and $80 \mathrm{mg} / \mathrm{d}$, but the fact that they had co-prescriptions for other antipsychotics raises the issue of how far olanzapine was actually responsible for these effects. However, it must be pointed out that the observational design of our study leave us with a positively selected sample. In fact, patients who do not tolerate olanzapine on any dose may have been discontinued from treatment early on. Therefore, the interpretation of these 
results must be restricted to a descriptive analysis of our sample and can not be generalized. Thus, olanzapine through its $\mathrm{H} 1$ antihistaminic and $5 \mathrm{HT} 2_{\mathrm{C}}$ antagonistic properties, has been reported in many studies (Qadri et al., 2006; Rodríguez-Pérez et al., 2002; Weiss et al., 2005) to increase appetite and disturb metabolism. Our study was not designed to assess these aspects (single assessment).

\section{Conclusion}

To conclude, our study yielded one main result: the linearity of the dose concentration relationship, even at very high doses of olanzapine. Our results also highlighted the need to find psychopharmacological explanations for the therapeutic response and tolerance of very high doses of olanzapine for TRS. The linearity of the dose-concentration relationship shows that pharmacokinetics cannot provide the whole explanation. High-dose responding and tolerating patients may have a specific brain dopamine D2 receptor occupancy profile that explains this clinical observation. Accordingly, the pharmacodynamic characteristics of olanzapine in TRS patients who respond to high doses now need to be assessed. It would be worthwhile conducting further research, such as PET studies, to explore those issues. They would doubtless open up new perspectives, such as highlighting regions of interest involved in olanzapine response and tolerance at high doses when resistance is described at low doses $(\leq 20 \mathrm{mg} / \mathrm{d})$. This would allow us to explore the neural basis of TRS and identify potential brain targets for innovative treatments such as deep brain stimulation.

\section{References}

1- Batail, J.-M., Bleher, S., Lozachmeur, C., Robert, G., Millet, B., Drapier, D., 2012. Very-high-dose olanzapine for treatment-resistant schizophrenia. O J Psych. 2 (4) 269271.

2- Bitter, I., Dossenbach, M.R., Brook, S., Feldman, P.D., Metcalfe, S., Gagiano, C.A., et al., 2004. Olanzapine versus clozapine in treatment-resistant or treatment-intolerant schizophrenia. Prog Neuropsychopharmacol Biol Psych. 28 (1) 173-180.

3- Callaghan, J.T., Bergstrom, R.F., Ptak, L.R., Beasley, C.M., 1999. Olanzapine. Pharmacokinetic and pharmacodynamic profile. Clin Pharmacokinet. 37 (3) 177-193.

4- Carrillo, J.A., Herrllo, A.G., Ramos, S.I., Gervasini, G., Vizcasin, S., Bencasi, J., 2003. Role of the smoking-induced cytochrome P450 (CYP) 1A2 and polymorphic 
CYP2D6 in steady-state concentration of olanzapine. J Clin Psychopharmacol. 23 (2) 119.

5- Hiemke, C., Baumann, P., Bergemann, N., Conca, A., Dietmaier, O., Egberts, K., et al., 2011. AGNP consensus guidelines for therapeutic drug monitoring in psychiatry: update 2011. Pharmacopsychiatry. 44 (06) 195-235.

6- Jang, E.H., Choi, J.Y., Park, C.S., Lee, S.-K., Kim, C.E., Park, H.J., et al., 2005. Effects of green tea extract administration on the pharmacokinetics of clozapine in rats. J Pharm Pharmacol. 57 (3) 311-316.

7- Kumra, S., Kranzler, H., Gerbino-Rosen, G., Kester, H.M., DeThomas, C., Kafantaris, V., et al., 2008. Clozapine and nhigh-dose"solanzapine in refractory early-onset schizophrenia: a 12-week randomized and double-blind comparison. Biol Psychiatry. 63 (5) 524-529.

8- Lerner, V., 2003. High-dose olanzapine for treatment-refractory schizophrenia. Clin Neuropharmacol. 26 (2) 58-61.

9- Martín J, Gómez JC, García-Bernardo E, Cuesta M, Alvarez E, Gurpegui M. 1997. Olanzapine in treatment-refractory schizophrenia: results of an open-label study. The Spanish Group for the Study of Olanzapine in Treatment-Refractory Schizophrenia. J Clin Psychiatry. 58 (11) 479-483.

10-Mauri MC, Volonteri LS, Colasanti A, Fiorentini A, De Gaspari IF, Bareggi SR. 2007. Clinical pharmacokinetics of atypical antipsychotics: a critical review of the relationship between plasma concentrations and clinical response. Clin Pharmacokinet. 46 (5) 359-388.

11-McGrath, J., Saha, S., Chant, D., Welham, J., 2008. Schizophrenia: a concise overview of incidence, prevalence, and mortality. Epidemiol Rev. 30 (1) 67-76.

12-Mcilwain, M., Wheeler, A.J., Russell, B.R., Harrisson, J., 2011. Pharmacotherapy for treatment-resistant schizophrenia. Neuropsychiatr Dis Treat. 7 135-149.

13-Meltzer, H.Y., Bobo, W.V., Roy, A., Jayathilake, K., Chen, Y., Ertugrul, A., et al., 2008. A randomized, double-blind comparison of clozapine and high-dose olanzapine in treatment-resistant patients with schizophrenia. J Clin Psychiatry.69 (2) 274-285.

14-Mueser, K.T., McGurk, S.R., 2004. Schizophrenia. Lancet. 363 (9426) 2063-2072

15-Nozawa, M., Ohnuma, T., Matsubara, Y., Sakai, Y., Hatano, T., Hanzawa, R., et al., 2008. The relationship between the response of clinical symptoms and plasma olanzapine concentration, based on pharmacogenetics. Ther Drug Monit. 30 (1) 35-40. 
16-Patel, M.X., Bowskill, S., Couchman, L., Lay, V., Taylor, D., Spencer, E.P., et al., 2011. Plasma olanzapine in relation to prescribed dose and other factors. J Clin Psychopharmacol. 31 (4) 411-417.

17-Perera, V., Gross, A.S., McLachlan, A.J., 2012. Measurement of CYP1A2 activity: a focus on caffeine as a probe. Curr Drug Metab. 13 (5) 667-678.

18-Qadri, S.F., Padala, P.R., Strunk, J.C., Boust, S.J., 2006. High-dose olanzapine orally disintegrating tablets for treatment-resistant psychosis. Prim Care Companion J Clin Psychiatry. 8 (4) 244-245.

19-R Development Core Team. R: a language and environment for statistical computing. [Internet]. Vienna, Austria: R Foundation for Statistical Computing; 2011. Available from: http://www.R-project.org/

20-Rodríguez-Pérez V, López Á, Blanco C, Peña C, López A, Abel A, et al. 2002. Olanzapine for the treatment of chronic refractory schizophrenia: A 12-month followup naturalistic study. Prog Neuropsychopharmacol Biol Psych. 26 (6) 1055-1062.

21-Saraceno, B., Levav, I., Kohn, R., 2005. The public mental health significance of research on socio-economic factors in schizophrenia and major depression. World Psychiatry. 4 (3) 181-185.

22-Schönthal, A.H., 2011. Adverse effects of concentrated green tea extracts. Mol Nutr Food Res. 55 (6) 874-885.

23-Solanki, R.K., Singh, P., Munshi, D., 2009. Current perspectives in the treatment of resistant schizophrenia. Indian J Psychiatry. 51 (4) 254-260.

24-Suzuki, T., Remington, G., Mulsant, B.H., Rajji, T.K., Uchida, H., Graff-Guerrero, A., et al., 2011. Treatment resistant schizophrenia and response to antipsychotics: a review. Schizophr Res. 133 (1-3) 54-62.

25-Tollefson, G.D., Birkett, M.A., Kiesler, G.M., Wood, A.J., 2001. Double-blind comparison of olanzapine versus clozapine in schizophrenic patients clinically eligible for treatment with clozapine. Biol Psychiatry. 49 (1) 52-63.

26-Van Os, J., Kapur, S., 2009. Schizophrenia. Lancet. 374 635-645.

27-Weiss, U., Marksteiner, J., Kemmler, G., Saria, A., Aichhorn, W., 2005. Effects of age and sex on olanzapine plasma concentrations. J Clin Psychopharmacol. 25 (6) 570574. 


\section{Table}

Table 1.

Clinical characteristics of the whole sample.

\section{Variable}

Age (years) $(N=50)$

Sex (male) $(N=50)$

Tobacco

Smokers $(n=46)$

Cigarettes/day $(n=46)$

PANSS $(n=41)$

Positive score

Negative score

Psychopathology score

Total score

ESRS $(n=42)$

Dyskinesia subscale

Dystonia subscale

Parkinsonism subscale

Akathisia subscale

UKU $(n=42)$

Psychic subscale

Neurological subscale

Neurovegetative subscale

Others

CGI

Severity scale $(n=41)$

Improvement scale $(n=37) 25(68 \%)$

\section{Sample}

$35.42 \pm 1.48$

$30(60 \%)$

$31(67 \%)$

$10.91 \pm 1.55$

$14.23 \pm 0.94$

$17.28 \pm 0.95$

$30.42 \pm 1.65$

$61.93 \pm 3.12$

$1(2.38 \%)$

$1(2.38 \%)$

$5(11.91 \%)$

$4(9.52 \%)$

$3.21 \pm 0.31 / 27$

$0.27 \pm 0.10 / 24$

$1.02 \pm 0.22 / 33$

$1.42 \pm 0.31 / 57$

$4.14 \pm 0.22$ 


\section{Figure}

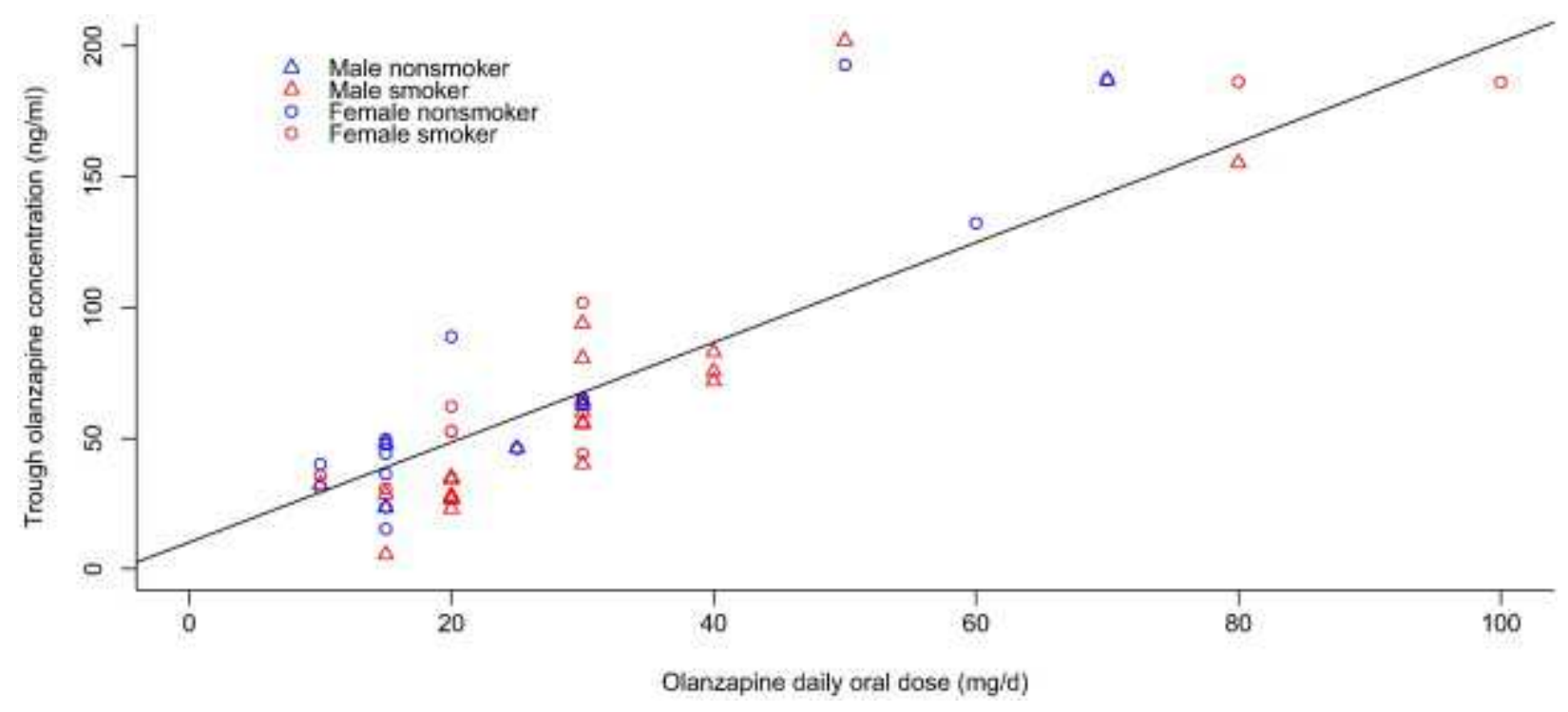

Fig. 1. Relationship between trough olanzapine concentration and daily oral dose of olanzapine. 